\title{
Entrelugares: pequeno inventário inventado sobre matemática e literatura
}

\section{In-between Places: A Small Invented Inventory on Mathematics and Literature}

\author{
Rafael Montoito* \\ ORCID iD 0000-0002-3294-3711
}

\begin{abstract}
Resumo
Este artigo fala das diferentes inter-relações possíveis entre Matemática e Literatura, mapeadas a partir da leitura de várias obras literárias. Seu objetivo é, à guisa das taxionomias fictícias elaboradas por Umberto Eco e Jorge Luis Borges, propor uma categorização dos diferentes modos como a Matemática se coaduna com a Literatura, chamados por Fux de entrelugares. A pesquisa, que mobilizou em sua análise autores tanto da Educação Matemática, quanto das áreas da literatura e da linguagem, apresenta como resultado três categorias: literatura com um viés matemático, literatura com termos matemáticos e literatura com estrutura matemática. Todas as categorias estão a serviço das seis justificativas que o artigo apresenta para se pensar um ensino de Matemática intermediado pela Literatura, das quais duas são discutidas aqui em maiores detalhes: a ideia de que ensinar a ler e escrever é um compromisso de todas as áreas e a necessária abertura de espaços para a criatividade na aula da Matemática.
\end{abstract}

Palavras-chave: Matemática e Literatura. Ler e Escrever nas Aulas de Matemática. Criatividade nas Aulas de Matemática. Entrelugares.

\begin{abstract}
This paper focuses on different possible interrelations between Mathematics and Literature which were delineated by reading several literary works. It proposes, based on Umberto Eco's and Jorge Luis Borge's fictional taxonomies, a categorization of the distinct ways Math and literature intertwine, called in-between places by Fux. This piece of research, which considered the ideas of some Mathematics Education researchers and other literature and language researchers in its analysis, points to three categories: literature with mathematical bias, literature with mathematical terms and literature with mathematical structures. All categories encompass the six justifications discussed by this article in order to reflect on Mathematics teaching mediated by Literature, two of which will be addressed more comprehensively: teaching reading and writing as an activity that must be performed by every school course and the need to stimulate creativity in Math classes.
\end{abstract}

Keywords: Mathematics and Literature. Reading and Writing in Math Classes. Creativity in Math Classes. Inbetween Places.

\section{Introdução: entrelugares habitados}

\footnotetext{
* Doutor em Educação para a Ciência pela Universidade Estadual Paulista "Júlio de Mesquita Filho" (UNESP/Bauru). Professor do Mestrado Profissional em Educação e Tecnologia, no Instituto Federal de Educação, Ciência e Tecnologia Sul-rio-grandense (IFSUL), Pelotas, RS, Brasil. Endereço para correspondência: Rua Paulo Marques, 403/201, Bairro Três Vendas, Pelotas, RS, Brasil, CEP: 96020-230. E-mail: xmontoito@gmail.com.
} 
Os livros não são feitos para que creiamos neles, mas para serem submetidos à investigação. Quando consideramos um livro, não devemos perguntar o que diz, mas o que significa (Umberto Eco - O Nome da Rosa).

Um aviador que, na infância, desenhou uma cobra que engolira um elefante. Um professor de Matemática que escreve romances nas horas vagas. Um grupo de personagens insólitos à caça de um monstrengo nunca antes avistado. Um astronauta perdido num planeta desconhecido. Um garoto indiano à deriva num barco, em meio a animais não domesticados. Amigos que tentam sobreviver a um ataque zumbi. Um papagaio manauara. Habitantes de um prédio com cem apartamentos. Cartas de um baralho de tarô.

Estes personagens - e alguns outros - moram nas boas bibliotecas. Suas histórias são lidas há anos por amantes da literatura, de idades distintas, ou contadas para quem ainda não sabe ler; algumas já foram adaptadas para o cinema e fazem eco, inclusive, no imaginário de pessoas que não as leram. Nestas histórias - e em algumas outras - é possível encontrarmos diferentes camadas de abordagens matemáticas, as quais vão desde uma menção superficial a um conceito até uma estrutura narrativa tão consistente quanto um teorema a ser demonstrado.

As possíveis inter-relações entre Literatura e Matemática aparecem pouco na sala de aula e o fazem com mais frequência nas Séries Iniciais. Arnold (2016), Costa (2015) e Montemór e Fernandes (2015), dentre outros, discutem como usar histórias infantis para a construção de conceitos matemáticos; entretanto, conforme se avança o olhar pelas séries escolares, percebe-se que esta abordagem vai minguando. Tal ação é injustificável, pois há uma variedade enorme de livros e autores que colocam à disposição do professor histórias que podem fomentar discussões matemáticas até nos cursos de formação de professores e de formação continuada.

Sendo assim, o objetivo principal deste artigo é propor uma categorização dos diferentes modos como a Matemática se coaduna com a Literatura, buscando fomentar uma discussão maior sobre o assunto entre os professores e estudantes de Matemática dos diversos níveis de ensino. Talvez alguém possa ler este artigo com desconfiança, pronto para argumentar que "literatura é literatura", não importando se o personagem principal é um professor de Matemática (como no conto O Crime do Professor de Matemática, de Clarice Lispector ou no romance A Fórmula Preferida do Professor, de Yoco Ogawa) ou se são histórias que se desenrolam através de um enigma matemático (como Uma História Embrulhada, de Lewis Carroll e O Escaravelho de Ouro, de Edgar Allan Poe).

Contudo, somos mais inclinados a concordar com Adam e Heidmann (2011), autores 
que comentam que os textos, em sua maioria, raramente se reduzem a um só gênero e a um só tipo de textualização, sobretudo os textos literários. Para eles, classificações como "contos", "tragédia", "epopeia" etc, ainda que tenham como função chamar a atenção do leitor para aquilo que pretende ler, não passam, na sua essência, de rótulos. Segundo estes autores, um texto está relacionado, normalmente, a vários gêneros - característica por eles chamada de genericidade - e, por isso, o leitor não deveria se preocupar tanto em classificá-lo numa determinada categoria, mas sim em observar as potencialidades genéricas que o atravessam, levando em conta sua textualidade (o modo como o texto dialoga com si mesmo) e sua transtextualidade (o modo como o texto dialoga com outros textos).

Perguntamo-nos, portanto, o porque de trabalhar com matemática na literatura. O
porquê de discutir conceitos e estruturas matemáticas em alguns autores que não
eram matemáticos profissionais e nem amadores. A única resposta possível é que o
estudo da literatura-matemática potencializa e traça um novo horizonte no campo e
nos estudos literários. Cria um espaço entre áreas diferentes do conhecimento e
possibilita a abertura para saber mais sobre o universo, os jogos, as trapaças e os
saberes, matemáticos e profissionais daqueles que trabalham nesse entrelugar.
Assim descobrimos obras sob um aspecto diferente da arte, novo ainda e não muito
explorado (FUX, 2016, p. 244).

Este artigo arrisca-se, pois, a falar um pouco destes entrelugares habitados por personagens que sabem ou não - ou não sabem que sabem - Matemática. Não nos ateremos a discutir se seus autores tinham ou não a intenção de abordar algum conteúdo em suas histórias. Assim como Dorothy descobre, numa passagem de $O$ Mágico de $\mathrm{Oz}$, que a Cidade das Esmeraldas era verde em função dos óculos que o mágico pedia à população que usasse, sugerimos que, na leitura deste texto, um par de óculos matemáticos seja colocado pelo leitor, para que ele aprecie aquilo que Montoito (2011) chamou de romances matemáticos: uma literatura que, explícita ou implicitamente, apresenta personagens ou passagens que podem ser interpretadas matematicamente.

Como em uma viagem, tomemos um andarilho que possui consigo dois mapas: um sobre "lugares literários" e outro sobre "lugares matemáticos"; a ele pediremos que sobreponha um mapa ao outro e constate quais regiões são entrelugares comuns às suas cartas de viagem - é por este esforço para compreender e conhecer estes entrelugares que justificamos nossa opção de, às vezes, trazer à tona referências dos campos da Literatura e da Linguagem e coaduná-las às da Matemática.

Além disso, este pequeno inventário inventado não tem a presunção de fornecer uma listagem de obras que encerre a discussão sobre o tema ou as possíveis classificações que aqui 
serão apresentadas, mas se aventura a discutir obras menos óbvias ${ }^{1}$. Nosso desejo é propiciar uma discussão que se delongue, que se ramifique, que esteja aberta a novas discussões e adições de obras.

Este inventário inventado foi inspirado em outras coletâneas imaginárias já presentes na literatura e é tão ficcional e irrestrito quanto o guia sobre terras e lugares lendários, organizado por Umberto Eco, ou a taxionomia dos seres imaginários, feita por Jorge Luis Borges $^{2}$. Contudo não é por ser ficcional que este inventário é menos crível: ele é um esforço convidativo a se adentrar nestes entrelugares, uma tentativa de organizar por semelhanças - e diferenças - a maneira como percebemos a Matemática nas obras literárias.

\section{Motivações para a abertura do inventário}

Nossas pesquisas sobre as inter-relações entre Matemática e Literatura remontam a 2006 quando, nos estudos de mestrado, começamos a nos perguntar em quais livros poderíamos encontrar resquícios de Matemática escondidos na narrativa, além de observar e estudar a relevância de a Literatura se fazer presente nos ambientes escolares (da Educação Infantil à Pós-Graduação). A partir daí, começamos a tecer tramas argumentativas, muitas vezes buscando autores fora da Educação Matemática, e estabelecendo diálogos interdisciplinares que têm, como objetivo principal, discutir a ideia de fomentar a leitura de textos literários nas aulas de Matemática.

Várias são as inquietações que nos perpassam nas investigações que já realizamos e que embasam a vontade de nos debruçarmos sobre o binômio literatura-matemática: (1) o reconhecimento de que ensinar a ler e a escrever é um compromisso que deve ser assumido e trabalhado por todas as disciplinas escolares, em suas linguagens e particularidades, em todos os níveis de ensino (NEVES; SOUZA et al., 2011; NACARATO; LOPES, 2009); (2) a abertura de espaços para que os estudantes de Ciências Exatas, cujas dimensões empírica, lógica e racional são priorizadas durante a formação acadêmica, tenham, também, possibilidade de desenvolver suas dimensões imaginária, mítica e simbólica, visando uma

\footnotetext{
${ }^{1}$ São bem conhecidos, pelos professores de Matemática, os livros $O$ Homem que Calculava, de Malba Tahan, $O$ Diabo dos Números, de Hans Magnus Enzensberger e Planolândia - um Romance de Muitas Dimensões, de Edwin Abbott Abbott. Considerando que alguns trabalhos sobre esses livros podem ser facilmente encontrados, optamos por discutir obras menos óbvias, o que não exclui a recomendação de leitura dessas, a quem se interessar pelo assunto.

${ }^{2}$ A literatura de Borges é vasta em referências e usos de conceitos matemáticos. Apesar de não ser comentada neste artigo, indicamos, a quem se interessar pelo assunto, a leitura de Borges y la Matemática, de Guillermo Martínez.
} 
educação mais heurística do ser (ALMEIDA, 2006; VERGANI, 2009); (3) a compreensão de que a Matemática e a Língua Materna estão mutuamente impregnadas e que, devido a isso, os conhecimentos desenvolvidos em uma área auxiliam no desenvolvimento dos da outra (MACHADO, 2001 e 2012); (4) a necessária formação, nos cursos de graduação, de um aluno leitor (MARIA, 2009; DI MARZO, 2013); (5) o reconhecimento da Matemática como elemento humano e artístico que inspira universos e narrativas (FUX, 2016; ODIFREDDI, 2007), (6) e a ideia de que a Literatura pode despertar no leitor a auto-ética (MORIN, 2011), tão necessária na sociedade atual.

Cada um desses assuntos - para os quais citamos apenas alguns autores dentre vários mereceria uma abordagem detalhada, porém destacaremos neste texto apenas os itens (1) e (2), com a intenção de fazer uma breve contextualização do tema, antes de apresentarmos o inventário, que é o cerne deste artigo.

\subsection{Ensinar a ler e escrever: compromisso de todas as áreas}

Sabe-se que a formação de leitores ocorre a partir da leitura de uma ampla diversidade de textos, cujos propósitos educativos são múltiplos (tais como informar, entreter, argumentar, persuadir etc.) e não se reduzem a apenas cumprir as exigências de um programa escolar. No entanto, é frequente encontrar em muitos ambientes de ensino o livro didático como, praticamente, a única proposta de leitura (CAMPOS; MONTOITO, 2010).

Ainda que textos alternativos ao livro didático apareçam como recurso didático mobilizado por alguns poucos professores, eles concentram-se nas suas áreas específicas: poesias, músicas e charges para o ensino de Língua Portuguesa; reportagens de jornais e revistas para o ensino de Geografia ou História; tabelas e índices para o ensino de Matemática, reportagens sobre meio-ambiente ou animais para o ensino de Biologia etc. Pouco se vê a respeito de, por exemplo, textos alternativos sendo utilizados fora das aulas de Literatura ou Língua Portuguesa (CAMPOS; MONTOITO, 2010, p.159).

Não se nega, em absoluto, que cada disciplina dos anos escolares tem seus símbolos e vocabulários próprios, os quais muitas vezes mudam sutilmente de significado quando aparecem em outra. $\mathrm{O} i$ que representa um dos vetores da base canônica de $\mathrm{R}^{3}$ em Geometria Analítica não é o mesmo $i$ da corrente elétrica em Física, e, maiúsculo, a primeira pessoa do singular na Língua Inglesa. Para entender essa diferença, o aluno precisa ler a informação em seu contexto - é este conhecimento do entorno que o fará perceber que, no primeiro caso, 
trata-se de uma grandeza vetorial; no segundo, de uma escalar; no terceiro, de um pronome pessoal.

A tarefa de ensinar a ler enunciados relativos a determinada disciplina é, pois, tarefa dos professores daquela disciplina. Sendo assim, entendemos que saber ler e escrever em Matemática vai muito além de interpretar gráficos e tabelas, ou extrair elementos do enunciado de um exercício, habilidades estas que, tomadas assim restritamente, podem acabar por alimentar o "alfabetismo funcional", o qual capacita o aluno a ter uma "função" na sociedade, a servi-la bem naquilo que ela demanda dele, dando eco a uma "educação matemática pautada apenas no aspecto utilitário do conhecimento matemático" (FONSECA, 2004, p. 27).

Várias são as relevâncias do porquê de se ensinar a ler em Matemática. Dentre tantas, podemos citar: compreender as informações comunicadas por outro pesquisador; interpretar criticamente dados amplamente divulgados, que se utilizam de noções de estatística e porcentagem para manipular a opinião da população; entender a pluralidade de significados de termos utilizados na mesma disciplina (o $x$, que pode ser uma variável, uma incógnita, a operação de multiplicação, o produto vetorial etc.) ou em disciplinas diferentes (o infinito, que para Matemática é uma quantidade numérica, na poesia pode ser um sentimento e, para Duns Scot, filósofo medieval, é um modo intrínseco de Deus); desenvolver capacidades de concisão, fruição e compreensão do lido, não travando nos enunciados etc.

A leitura comumente feita em aula, a qual se resume praticamente a responder as perguntas elaboradas por outro (o professor ou o enunciado), "inibe a autonomia do leitor (...), não contribuindo para que os alunos se tornem leitores autônomos em Matemática" (FONSECA; CARDOSO, 2009, p. 69). Na opinião de Solé (apud FONSECA; CARDOSO, 2009), há uma variabilidade de objetivos a serem alcançados pelo incentivo da leitura nas aulas de Matemática, dentre os quais está o prazer de ler sobre Matemática. Muito além disso, aprender a ler em Matemática também pode ser visto como um ato social, à medida que possibilita compreender a Matemática de outros povos e culturas, distantes ou não no tempo, coligando saberes e criando uma identidade de respeito às manifestações e apropriações diferentes daquelas que são abordadas no ambiente escolar.

No outro extremo desta equação, advogamos acerca da necessidade de se ensinar a escrever em Matemática. Enquanto área do conhecimento humano, a Matemática possui uma linguagem própria, dotada de códigos e de uma gramática próprios, utilizada por uma certa comunidade (CORRÊA, 2009). Sustentada sobre a língua materna, a linguagem matemática coexiste com ela e é essa coadunação que lhe atribui significados: $A, v, B, \sim, \rightarrow$ são símbolos 
que, apenas quando organizados em uma sentença - para a qual se necessita da língua materna para elaborar e compreender -, geram uma afirmação matemática. As premissas $A v$ $B$ e $\sim A$ são primeiramente lidas na língua materna (existe ( $A$ ou $B$ ) e não existe $A$ ) para, a partir dessa apropriação, gerarem a conclusão portanto existe $B(\mathrm{~A} \vee \mathrm{B}, \sim \mathrm{A} \rightarrow \mathrm{B})$. Este é apenas um rápido exemplo que mostra que a linguagem matemática

\begin{abstract}
tem registros orais e escritos e, como qualquer linguagem, apresenta diversos níveis de elaboração, consoante à competência dos interlocutores: a linguagem matemática utilizada pelos "matemáticos profissionais", por traduzir ideias de alto nível, é mais exigente do que a linguagem utilizada para traduzir ideias numa aula. Da mesma forma, a linguagem natural assume registros de complexidade diferente, dependendo da competência dos falantes. Há, porém, diferenças marcantes entre a linguagem natural e a linguagem Matemática: uma delas é que esta não se aprende em casa, desde pequeno, mas, sim, na escola (CORRÊA, 2009, p. 95).
\end{abstract}

Deste modo, se pensarmos na formação de um aluno como uma vivência que lhe possibilitará inserir-se criticamente no mundo, ultrapassando a dimensão utilitária da Matemática e, quiçá, tornando-se pesquisador da área, precisamos criar estratégias que o façam desenvolver sua escrita em e sobre Matemática. Para que um aluno consiga, de maneira não trivial, comunicar suas pesquisas feitas em iniciação científica, mestrado ou doutorado, é fundamental que ele tenha trilhado um caminho que o preparou para escrever sobre estes assuntos e o incitou a saber controlar códigos, significados, usos e gramática próprios da linguagem matemática. Com isso, retomamos o exposto anteriormente: essa é uma responsabilidade do professor de Matemática, que pode até ser partilhada por professores de outras áreas, mas da qual esse nunca poderá se isentar.

A escrita, quando pensada junto à Matemática, não se refere apenas à elaboração de relatórios, artigos e demais produções textuais que a Academia reconhece e valoriza. Outras práticas podem ser encontradas nos trabalhos de Viana (2017) e Santos (2009).

A primeira pesquisadora relata que estimulou seus alunos a construírem portfólios, a partir dos quais pôde ter uma compreensão diferente de como se dava a aprendizagem deles e as relações que estabeleciam com os tópicos estudados no Ensino Fundamental; já a segunda conta que tem utilizado diferentes práticas com seus alunos do Ensino Superior, tais como a elaboração de mapas conceituais e glossários. Segundo o que Santos observou em suas turmas, ao escrever textos desprovidos de rigor matemático, muito embora falassem de Matemática, os alunos conseguiam traduzir melhor as informações estritamente técnicas, além de se sentirem mais à vontade e menos ameaçados pelo conteúdo.

Narrativas, crônicas, poesias, charges etc. podem, igualmente, ser incorporadas às aulas de Matemática, auxiliando os alunos a adquirirem domínio da língua materna e dos seus diferentes estilos e pavimentando o caminho para uma escrita em e sobre Matemática. Santos 
(2014) e Balladares (2014) apresentam mais uma opção: as histórias em quadrinhos. Essas múltiplas abordagens convidam o aluno à autonomia da produção textual e à criatividade, que é o próximo ponto a ser abordado.

\title{
2.2 Abertura de espaços à criatividade
}

As ideias de longas listas de exercícios, de seguir os modelos e algoritmos para construir a aprendizagem e as auras de infalibilidade e inquestionabilidade da Matemática fazem parte do ensino tradicional dessa disciplina. Cristalizadas no tempo, exercem resistência às novas metodologias, teorias e tecnologias pensadas para ensinar Matemática. A utilização de softwares, a produção e edição de vídeos feitos por estudantes, a criação de jogos, a elaboração de maquetes, mandalas etc. são propostas educativas, apresentadas aos alunos por alguns professores, que abrem espaço para a criatividade nas aulas de Matemática. Outra possível abordagem é a Literatura, que desejamos discutir por este texto.

Pesquisadores da relação entre Matemática e linguagem reconhecem que "a poesia e a matemática compartilham não somente a medida (no caso de versos rimados), mas também harmonia, beleza, jogo, artifício e criatividade. Por isso muitos poetas e matemáticos têm comparado a experiência de demonstrar um teorema com a de construir um poema" (URBANEJA, 2005, p. 3) ) $^{3}$ e tantos autores têm se apropriado da Matemática como elementos pertencentes às suas histórias ou constitutivos das estruturas de suas narrativas, criando entrelugares acessíveis pelas portas da criatividade (de quem as escreve e de quem as lê).

A opção por trabalhar de maneira simbiótica a Literatura e a Matemática, quando possível, é uma maneira de incentivar a ler e escrever nas aulas de Matemática e, também, a valorização de um aspecto muito importante que tem ficado relegado ao segundo plano: o reconhecimento da imaginação e da afetividade na construção de ideias, conceitos e visões de mundo e, portanto, de ciência.

\begin{abstract}
Privilegiando o cálculo, a objetividade e a lógica e recusando tudo o que é entendido como ilusório, fantasioso e irreal, o ensino formal opera uma redução em relação às potencialidades cognitivas do sujeito humano. Isso porque somos constituídos por dois itinerários do pensamento que se parasitam permanentemente: um empíricológico-racional, outro mítico-simbólico-mágico. Qualquer redução de um desses polos do espírito ao outro compromete a amplitude de nossas concepções de mundo, nos faz andar com uma perna só. O ilusório sozinho nos encerra no delírio. A razão sozinha se torna racionalização, se embrutece, fica cega para tudo o que não é cálculo, regra, lógica (ALMEIDA, 2006, p. 12).
\end{abstract}

\footnotetext{
${ }^{3}$ Neste artigo, todas as citações de textos que não estavam escritos na língua portuguesa (ver referências bibliográficas) foram traduzidas por nós.
} 
Portanto, obras literárias nas quais se evidenciem traços matemáticos podem servir para despertar no aluno um olhar diferente com relação à disciplina, à medida que lhe apresentam ideias e conteúdos que fogem ao esquema definição-exemplos-generalizaçõesexercícios. A Literatura é uma das vias de acesso à tríade do mítico-simbólico-mágico, pois ela convida o leitor a habitar lugares desconhecidos e, ao adentrá-los, o leitor não tem conhecimento do que se passará e nem de quais sentimentos seus serão tocados pelo texto. A imprevisibilidade se dá porque "as ficções não são o lado irreal da realidade, e nem algo oposto à realidade (...). São condições que tornam possíveis a produção de mundos de cuja realidade, por sua vez, não se pode duvidar" (DI MARZO, 2013, p. 22), mas para os quais é difícil se estar totalmente preparado.

O ambiente imaginário, os personagens fictícios, as situações que beiram ao absurdo misturadas às informações reais e organizadas, conforme as exigências do rigor matemático que, lembremos, se apresentam em diferentes níveis de complexidade nos textos possibilitam ao leitor usar da sua criatividade para compor cenários, desvendar enigmas e construir aprendizagens. Não obstante, a leitura é apoiada por duas faculdades do pensar, segundo Smith (apud MARIA, 2009): prever e conjecturar, pois o leitor, mesmo inconscientemente, pensa os próximos acontecimentos da história antes de conhecê-los pelo texto.

Prever e conjecturar são ações também indispensáveis para a aprendizagem da Matemática. Tal como comentado com relação aos textos, o aluno, ao deparar-se com um novo conteúdo, estabelece relações de semelhança ou diferença entre ele e outros tópicos estudados, faz previsões dos possíveis desdobramentos teóricos e práticos dos exercícios que precisará resolver e, muitas vezes, questiona os caminhos escolhidos por ele mesmo neste processo e conjectura outras linhas de ação. Essa semelhança de posturas frente a um texto e frente à aprendizagem de conteúdos matemáticos - que, em ambos os casos, aciona a criatividade do aluno em seu modo de se prostrar defronte a eles - é mais um argumento a favor de se levar a Literatura para as aulas de Matemática.

Falar em criatividade hoje é falar em irrupção da novidade, qualquer que seja o grau - ou a abrangência - desse "parto" que inaugura a coisa recém-nascida. A ruptura com o mundo normalizado/cotidianizado/convencionado tem sido operada de três formas: por meio do transe, da arte e da criatividade. Há muito tempo a nossa civilização proíbe o transe. Certas formas de arte perderam o vigor da significação ao enlear-se nos meandros do elitismo e do marketing. Resta-nos apenas a esperança difusa daquilo que designamos por criatividade (VERGANI, 2009, p. 179),

que é uma característica inerente ao ser, mas comumente deixada fora das aulas de Matemática. 
Sem possibilitar espaços em que o aluno possa trazer a sua criatividade para o estudo da Matemática, teremos, como resultado, apenas a repetição de padrões. Contudo, como apontou Vergani (2009), é necessário romper com o mundo normatizado, dando vazão à criatividade: ousar, criar na arte, experienciar, alargar os campos científicos, construir conexões entre diferentes saberes etc. são ações facilmente observáveis nos entrelugares habitados pela Matemática e pela Literatura.

Tendo exposto em pormenores - mas não esgotado - dois dos seis itens que nos motivam a conhecer e trabalhar nestes entrelugares, convidamos o leitor, agora, a conhecer algumas peças deste nosso pequeno inventário.

\section{Pequeno inventário inventado sobre matemática e literatura}

O inventário que se segue tem, por objetivo, propor uma categorização dos diferentes modos como a Matemática se coaduna com a Literatura, buscando fomentar uma discussão maior sobre o assunto entre os professores e estudantes de Matemática, dos diversos níveis de ensino. Não é escopo deste artigo discutir suas possíveis apropriações e transposições para a sala de aula, visando ao ensino de conteúdos. O inventário deve ser lido como um guia de passeio pelos entrelugares, um convite ao leitor para que pense nestas relações que mapeamos e, na medida do possível, ajude-nos a expandir este mapa com outros títulos. Pretendemos suscitar, no leitor, curiosidade pelos livros comentados e, assim, cativar seu olhar para pensar conosco o binômio Matemática e Literatura.

Há, em cada uma das categorias que serão expostas, mais títulos do que a quantidade que comentaremos: a escolha daqueles aqui apresentados não se deu por nenhuma razão editorial (serem mais conhecidos, mais novos ou terem vendido mais cópias), mas por terem sido os primeiros que ascenderam à nossa memória de leitor.

A necessidade de pensar categorias distintas surgiu de nossas próprias leituras, quando nos demos conta de que a Matemática se fazia perceber nos romances matemáticos de maneiras diferentes. O esforço em estabelecer demarcações entre elas se justifica ao pensar que, caso os professores desejem trabalhá-las com seus alunos em algum momento, elas apresentarão níveis distintos de conteúdos e complexidades matemáticas para o aluno e, portanto, exigirão do docente tratamento diferenciado.

Outra justificativa desta categorização é poder pensar as relações de uso dos termos e conceitos matemáticos por conta dos autores dos livros, o que pode, em outro momento, levar a estudos: (1) que comparem os diferentes significados que uma palavra assume quando está 
inserida em um contexto matemático, comparando-os com os significados atribuídos pela língua materna; (2) sobre as relações de saber estabelecidas entre os autores e suas obras; (3) acerca da Matemática como um elemento fantasioso - mas, nem por isso, irreal - e constitutivo de narrativas etc.

Contudo, vale ressaltarmos a possibilidade de um livro irromper a demarcação de uma categoria e passar à outra, ou pertencer a mais de uma, dependendo do trecho escolhido e do tratamento dado a ele. Sendo assim, esses entrelugares são flexíveis e podem ajustar-se ao olhar e à expectativa dos leitores, bem como às vivências que esse traz, consigo, de leituras prévias.

\subsection{Literatura com um viés matemático}

Nesta primeira categoria inventariamos narrativas nas quais é possível perceber alguns resquícios de Matemática, muito embora não apareçam, explicitamente, termos ligados a ela. É o caso para o qual o leitor precisa, como exposto no começo deste artigo, colocar seus óculos de lentes matemáticas e dirigir um olhar interpretativo para a passagem lida. Captar, das sutilezas de um texto, uma ideia matemática é um modo válido de o educador matemático colocar-se no mundo à sua volta e relacionar-se com ele - modo esse que talvez não seja igual ao de outra pessoa, a quem o mesmo excerto do texto pode sussurrar relações outras.

Nosso primeiro exemplo vem do bastante conhecido $O$ Pequeno Príncipe. Escrito por Antoine de Saint-Éxupery, narra a história de um principezinho que deixa o seu planeta (o asteroide B612) e chega ao nosso; aqui na Terra conhece, dentre outras personagens, um aviador, que é o narrador de toda a trama. Já no começo há uma cena que sintetiza um dos conceitos básicos da Topologia: o desenho que o aviador, quando criança, faz da jiboia antes e depois de ela engolir um elefante caracteriza uma superfície isotópica.

Popularmente conhecida como "geometria elástica" (COUTINHO, 2001), um dos objetos de estudo da Topologia diz respeito à topologia da superfície, isto é, às propriedades da superfície que se mantêm inalteradas apesar das deformações a ela impostas ${ }^{4}$.

Ao desenhar a jiboia que havia engolido, "sem mastigar, a presa inteira" (SAINTEXUPÉRY, 1988, p. 9), o aviador a esticou e a inflou: na sua imaginação e nos traços de seu

\footnotetext{
${ }^{4}$ São quatro estas deformações: esticar ou inflar a superfície ou partes dela; encolher a superfície ou partes dela; entortar a superfície ou partes dela; cortar a superfície segundo uma linha suave nela demarcada e, posteriormente, colar novamente, uma na outra, as bordas geradas por este recorte, resgatando a superfície original com a linha demarcada (SAMPAIO, 2008).
} 
desenho, a serpente, alongada e rastejante em seu aspecto normal, é deformada, ficando seu corpo com a forma condizente à do um elefante que engolira. A jiboia antes de engolir o elefante representa uma superfície; a jiboia, depois de o engolir, outra, e estas superfícies são isotópicas porque a segunda é obtida através de um número finito de deformações possíveis. Como uma superfície foi obtida a partir da outra, ambas são topologicamente equivalentes.

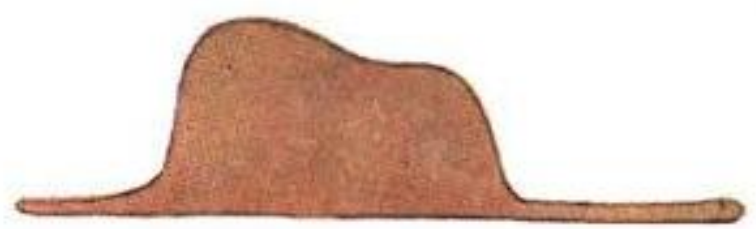

Figura 1 - Desenho do aviador, quando menino, sobre uma jiboia que engolira um elefante Fonte: O Pequeno Príncipe (SAINT-EXUPÉRY, 1988, p. 9).

O inegável viés topológico que emerge nesta parte da narrativa pode ter sido criado intencionalmente por Saint-Exupéry. Todavia, ainda que não possamos ser taxativos com relação à intenção do autor, não há como negar que, àqueles que sabem topologia, tal passagem desvela-se como um exemplo pertinente.

Outro exemplo, também sutil, aparece na trilogia de Haruki Murakami. A história de 1Q84 tem três personagens principais: Tengo, um professor de Matemática que escreve romances nas horas vagas; Aomame, uma assassina de aluguel; Fukaeri, jovem autora de um romance que Tengo ajuda a reescrever para concorrer a um concurso literário.

O fato de um desses personagens ser um professor de Matemática já traz, para o texto, algumas referências e "macetes" conhecidos de quem ensina essa disciplina, mas aqui estamos interessados em discutir um elemento importantíssimo deste universo narrativo: as histórias de Tengo e de Aomame transcorrem paralelamente - estariam eles em universos paralelos? - e, em determinado momento, ele intui, devido a coisas que acontecem à sua volta, que não está no mundo real.

Foi então que Tengo percebeu que, num canto do céu, bem próximo à lua, havia uma outra lua pairando. No começo, achou que era uma ilusão de ótica, ou um tipo de ilusão provocada pela luz. No entanto, depois de olhar várias vezes, constatou que havia uma segunda lua com contornos bem-definidos. Tengo ficou perplexo e, com a boca entreaberta, observou a direção em que se encontravam as luas. Sua mente não conseguia processar o que ele via (MURAKAMI, 2013, p. 292).

As duas luas estão, segundo o texto, bem próximas, o que quer dizer que elas não se tangenciam ou se intersectam. Tópicos do cálculo de várias variáveis vêm à tona se consideramos que as luas $\left(L_{1}\right.$ e $\left.L_{2}\right)$ podem ser representadas por esferas cujos centros $\left(C_{1}\right.$ e $C_{2}$, respectivamente) podem ser unidos por um segmento de reta $r$ : no ponto de intersecção de $r$ com $L_{l}$ há um vetor gradiente, do mesmo modo que ocorre no ponto de intersecção de $r$ com 
$L_{2}$ e eles têm direções paralelas. Caso as luas (esferas) se tangenciassem, além de os gradientes serem paralelos, as equações que as representariam teriam que possuir um ponto em comum. Como sublinha Stadler (2007), a literatura está cheia de deliciosas mensagens, implícitas, de conteúdos de Matemática para todos os níveis de estudo e, aqui, Murakami escondeu algumas delas em meio ao firmamento.

Para fechar (momentaneamente) essa categoria, trazemos o livro Caça ao Turpente, de Lewis Carroll. Este poema nonsense $e^{5}$ narra, em oito capítulos, a caçada a um bicho incomum, o turpente ${ }^{6}$ do título. Carroll é bastante conhecido pelos estudiosos de diversos campos da Matemática, em especial os da Geometria Euclidiana e da Lógica Simbólica, uma vez que escreveu algumas obras, com roupagem literária, para discutir estas disciplinas.

A nós não passou despercebida, pois, nesta obra, uma alusão à teoria de conjuntos. Tomadas num único grupo, percebemos que as personagens são elementos de um conjunto que tem sua lei de formação bem clara: todas têm o nome iniciado pela mesma letra. Se, na versão original, a escolha de Carroll foi pelo $B$, o tradutor responsável pela edição brasileira optou por $C$, mantendo esta característica: Campainha, Chineleiro, Corretor, Carambola, Caixa, Castor, Confeiteiro e Carniceiro compõem o grupo que sonha caçar o monstrengo. Ressaltamos, mais uma vez, a ideia de que esta narrativa apresenta um viés matemático identificado mais facilmente por aqueles que trabalham com esta disciplina; entretanto, ainda que o tradutor não o tenha identificado, esta imposição textual foi tão forte que ele não pôde menosprezá-la e teve que achar uma solução equivalente para a tradução da edição brasileira.

Comentadas estas três obras, esperamos ter deixado clara a característica principal adotada para a construção da primeira categoria deste inventário: não há, nos textos, menção alguma sobre conteúdos matemáticos; todavia, eles se apresentam de maneira embrionária, oculta e sutil, à espera de um desvelamento que só poderá ser feito por quem tem, no seu arcabouço teórico, um conhecimento matemático. O leitor, ao articular conjuntamente no ato da leitura o texto e seus conhecimentos matemáticos, é capaz de perceber um viés matemático nas narrativas e, por isso, conferir a elas significados plurais que permanecem ocultos para outros leitores não acostumados a procurar indícios da Matemática na Literatura.

\footnotetext{
5 Tomamos, aqui, a definição de nonsense, segundo Gattegno (1990), em que o termo não se refere a uma ausência de sentido, mas mais a infinidade de sentidos possíveis.

${ }^{6}$ Montoito (2013) comenta que o monstrengo caçado (turpente, na edição brasileira; snark, no título original) nunca é descrito no texto e não aparece em nenhuma das ilustrações do livro. O próprio Carroll também teria feito pouco caso sobre isto, privilegiando narrativamente a composição e sonoridade da palavra snark, em detrimento da representação "física" do animal. Dentre as possíveis teorias comentadas pelos estudiosos das obras carrollianas, a mais comumente aceita é que snark seja uma composição das palavras snake (cobra) e shark (tubarão), o que daria, na interpretação do tradutor brasileiro, o turpente do título (tubarão e serpente).
} 


\subsection{Literatura com termos matemáticos}

Esta segunda categoria é composta por livros que apresentam termos matemáticos de uma maneira mais clara, os quais invocam conceitos ou conteúdos matemáticos. Desta vez é possível encontrar, nos livros nela agrupados, definições, problematizações e/ou aplicações de tópicos que fazem parte do currículo de Matemática. Essa menção - agora explícita, diferentemente da categoria anterior - não garante que o leitor conseguirá extrair dela todas as informações matemáticas ali contidas, pois isso depende de quem é este leitor, de qual lugar ele lê e da bagagem de conhecimentos que traz consigo. No entanto, o texto lhe acena com elementos matemáticos, talvez o convidando a adentrar mais neste entrelugar e construir outras relações interpretativas com a história.

Não estamos dizendo que a simples citação de palavras conhecidas (por exemplo: quadrado, paralelas, círculo, média etc.) é suficiente para inventariarmos um livro nesta categoria; a seleção é mais rigorosa, pois considera que os termos e seu entorno no texto trazem à superfície um conhecimento matemático já sistematizado ${ }^{7}$.

O primeiro exemplo vem de O Planeta dos Macacos ${ }^{8}$, de Pierre Boulle (2015). Nesta ficção científica francesa, um astronauta chega a um planeta no qual os macacos são a raça inteligente e, os humanos, desprovidos de linguagem e intelectualidade tal qual conhecemos na Terra, as bestas caçadas e utilizadas como cobaias. Ulysse, o astronauta, não consegue, na primeira parte da narrativa, conversar com Zira, a macaca que coordena o laboratório de experiências no qual ele está preso em uma jaula. Para fazer contato com ela e lhe mostrar que ele não é um ser irracional como os demais humanos daquele planeta, Ulysse apela à Matemática. Primeiramente esboça a representação geométrica do teorema de Pitágoras e, depois, mostra que tem conhecimentos mais aprofundados sobre o assunto:

\footnotetext{
Numa página do caderno, desenhei o melhor que pude as três cônicas, com seus eixos e núcleos: uma elipse, uma parábola e uma hipérbole. Depois, na página contígua, tracei um cone de revolução. Lembro aqui que a interseção de um corpo desse tipo num plano compõe uma das três cônicas, dependendo do ângulo de corte. Fiz a figura no caso da elipse e, voltando ao meu primeiro desenho, apontei com o dedo a curva correspondente para minha macaca extasiada (BOULLE, 2015, p.85$86)$.
}

A comunicação feita através da "linguagem universal" da Matemática deu resultado:

\footnotetext{
7 Mesmo tendo dito anteriormente que este artigo não se preocuparia em comentar e exemplificar como a literatura poderia ser utilizada para o ensino de Matemática nas salas de aula, vale ressaltarmos que os livros/excertos desta categoria são os que, a nosso ver, podem ser melhor transpostos para atividades didáticas.

${ }^{8}$ Como acontece quase todas as vezes em que um livro é adaptado para o cinema, há substanciais diferenças entre a narrativa e o filme. Nossa análise detém-se, pois, no texto escrito.
} 
Ulysse diz que se estabeleceu, entre ele e a macaca, "uma comunicação espiritual (...) intermediada pela geometria" (BOULLE, 2015, p. 86). A figura do cone intersectado por um plano, em diferentes momentos com ângulo de inclinação distintos, é facilmente encontrada em livros textos de Geometria Analítica e, até mesmo, em tópicos sobre História da Matemática, uma vez que os gregos já estudavam estas relações na Antiguidade. Aqui, descrita de maneira literária, evoca, na mente do leitor que já estudou este conteúdo, uma gama de saberes relativos à construção das curvas cônicas.

Um exemplo, agora de número irracional, aparece nas páginas de $A$ Vida de Pi. Escrita por Yann Martel (2004), a história é uma fábula sobre o naufrágio de um garoto indiano que, à deriva num bote salva-vidas, precisa dividir seu espaço com uma hiena, um orangotango, uma zebra e um feroz tigre-de-bengala. O protagonista desta narrativa que fala de sobrevivência, de tolerância e das relações entre o homem e a natureza é um jovem de dezesseis anos que, quando estava na escola, se apresentava para os colegas da seguinte maneira:

\footnotetext{
Levantei-me da carteira e encaminhei-me às pressas para o quadro-negro. Antes que o professor pudesse dizer uma palavra, peguei um pedaço de giz e disse enquanto escrevia:

Meu nome é

Piscine Molitor Patel, conhecido de todos como - e sublinhei as duas primeiras letras do meu nome - Pi Patel.

Para não deixar dúvida, acrescentei

$\pi=3,14$

e desenhei um grande círculo, que depois dividi em dois com um diâmetro, para evocar aquela aula de geometria básica (MARTEL, 2004, p. 38).
}

Seus colegas parecem não ter esquecido a alusão que o nome do colega fazia ao diâmetro da circunferência. Pi, que é também o narrador da história, conta que, após algumas repetições desta apresentação, os colegas começaram a fazer um coro com ele num crescendo que atingia o clímax: “'Três! Vírgula! Um! Quatro!’, enquanto eu escrevia o mais rápido que podia. Eu terminava cortando o círculo com tanto vigor que pedaços de giz chispavam" (MARTEL, 2004, p. 39).

Tal qual o exemplo anterior, vemos que a narrativa faz mais do que simplesmente evocar os termos matemáticos $\pi$, círculo e diâmetro: ela encerra, em si, um conhecimento matemático, uma parte daquilo que estudamos e das relações que já estabelecemos na construção deste saber.

Piscine - que, indubitavelmente, não esquecia o que havia aprendido nas aulas de geometria - associou seu apelido à construção geométrica do irracional $\pi$. Todavia, o fato de ele não ter problematizado que esta constante é obtida através da divisão do perímetro de qualquer circunferência pelo seu diâmetro leva-nos à questão: devemos entender que a 
personagem, tendo aprendido isto em aulas anteriores, tratou isso como sabido ou desconfiar de um deslize do autor, o qual teria esquecido parte desta construção? De qualquer modo, posto o texto, o leitor com conhecimento matemático se faz este questionamento (o qual também pode ser feito para algum aluno que o leia): as informações contidas neste excerto são suficientes para definir $\pi$ ?

Alguns outros livros possuem a particularidade de suscitar questionamentos a partir dos próprios títulos: O Teorema Katherine (de John Green, 2013), Lemniscata - o Enigma do Rio (de Pedro Drummond, 2007) e A Solidão dos Números Primos (de Paolo Giordano, 2009), dentre outros, são exemplos de narrativas que já se apresentam, ao leitor que sabe Matemática, de maneira diferente do que aqueles que não sabem.

Nestes, os autores partem de conceitos matemáticos para construir a história e, se em algumas vezes tais conceitos são utilizados metaforicamente, em outras são tomados como parte constitutiva da trama, ou seja, lhes é atribuído um significado que extrapola o matemático para adentrar na composição narrativa, agregando-lhes um valor literário.

Pouco poderíamos comentar sobre estas obras, neste momento, sem entregar, a um leitor em potencial, as surpresas que estas narrativas escondem. Daremos atenção, portanto, às pequenas reflexões que poderiam surgir do entrecruzamento de seus títulos com as sinopses que aparecem em suas capas: por que Green fala de teorema, e não de axioma ou corolário?; por que uma curva é parte de um mistério que tem, como um dos cenários, o Rio do século XVI?; por que o romance de Alice e Mattia é comparado à definição de números primos gêmeos?

Ainda nesta categoria, inventariamos os livros escritos com o claro propósito de ensinar algum conteúdo ao leitor (História da Matemática, Lógica, Cálculo, Estatística etc.). Não estamos nos referindo a paradidáticos, mas a narrativas mais complexas, pensadas para apresentar ao estudante conteúdos com uma roupagem não usual, já que "os temas do mundo são pouco numerosos, mas os arranjos são infinitos" (MARIA, 2009, p. 156), o que possibilita dar um tratamento literário aos conteúdos matemáticos.

Autores deste tipo de livro parecem considerar que, para melhor ensinar algo, é preciso estabelecer ligações entre a afetividade e a racionalidade do leitor - dois polos do ser já discutidos anteriormente quando falávamos das dimensões humanas e do exercício da criatividade - na criação de suas narrativas. Uma história mais longa, algumas delas com o apoio massivo de ilustrações, permite que o leitor sinta-se mais perto das personagens e, consequentemente, daquilo que precisaria estudar e aprender. Esta relação de proximidade dáse inconscientemente devido ao fato de que 
um livro, também uma peça de teatro ou um filme, contém, pelo menos, dois componentes: personagens e trama. Personagens vivos, verossímeis, que encarnam o pensamento e as paixões que vivem na cabeça e no coração dos homens (...) E, também, uma trama que nos mantém atentos, preso a ela. Queremos saber o que é que vai acontecer na próxima página. São os personagens e a trama que nos fazem desejar, como ocorre sempre com as boas narrativas, que o livro não acabe nunca (LEGUINA, 2006, p. 54-55).

Trazemos, como exemplos, os livros O Teorema do Papagaio (de Denis Guedj, 1999), Logicomix - Uma Jornada Épica em Busca da Verdade (de Apostolos Doxiadis e Christos H. Papadimitriou, 2010), Zombies \& Calculus (de Colin Adams, 2014) e An Adventure in Statistics: The Really Enigma (de Andy Field, 2016) ${ }^{9}$.

No primeiro, um grupo de crianças parisienses ajuda um livreiro a organizar os livros que um amigo seu, professor de Matemática, lhe enviou de Manaus, antes de desaparecer juntamente com seu papagaio; à medida que organizam os títulos recebidos, as crianças vão percorrendo a linha temporal da História da Matemática desde a Antiguidade até os dias atuais. O segundo é uma história em quadrinhos sobre a vida de Bertrand Russell e sua dedicação para estabelecer os fundamentos lógicos de todos os princípios da Matemática e a história traz outros personagens que passam pela vida de Russell e suas ideias, tais como Gottlob Frege, David Hilbert, Kurt Gödel e Ludwig Wittgenstein.

O terceiro livro é a história do fictício professor Craig Williams que, quando se vê em meio a um apocalipse zumbi, usa seus conhecimentos de Cálculo para tentar salvar sua vida e as de alguns alunos, o que inclui diferenciais, integrais, coordenadas polares, regra de L’Hospital, vetores etc. Já o quarto título, bastante rico em ilustrações, conta a história do casal Zach, um músico que não entende nada de Matemática, e Alice, uma geneticista que é especialista em Estatística; quando ela desaparece após ter feito uma importante descoberta, ele se dá conta de que terá que aprender Estatística para buscar, na pesquisa dela, pistas de onde e como reencontrá-la.

Assim, encerramos os exemplos desta categoria (sem, claro, esgotá-la, pois há vários outros títulos que poderiam ser inventariados nela). De abordagens pontuais em trechos da narrativa até a construção completa de uma história em torno de determinado conteúdo matemático, sua característica principal é que, através da explicitação dos elementos matemáticos, convida o leitor a pensar neles, tanto enquanto conteúdo, quanto com relação à maneira como foram apropriados pelos autores para serem inseridos nas tramas.

\footnotetext{
${ }^{9}$ Desconhecemos, até o momento, qualquer tradução para a língua portuguesa dos dois últimos livros citados.
} 


\subsection{Literatura com estrutura matemática}

A última categoria fala de livros cujas estruturas narrativas foram pensadas a partir de algum conteúdo matemático, isto é, a história se organiza e se desenvolve segundo as propriedades matemáticas do corpo teórico que o autor escolheu como modelador do seu universo literário. Elas vão além da referência ou da alusão metafórica de um conteúdo matemático, como acontecia na categoria anterior, pois de fato são estruturas matemáticas.

Os autores cujos livros fazem parte deste grupo viram na Matemática um potencial não usual e a ressignificaram em forma literária. Poderíamos dizer que este caso é o mais elaborado, dentre as três categorias que elencamos, uma vez que estas histórias, além de lidas, podem também ser estudadas. Os três romances que citaremos como exemplos surgem na segunda metade do século passado e incorporam, em suas concepções, os desejos à época pulsantes em todas as artes: ousar, inovar e romper com o já conhecido.

A Vida Modo de Usar, de Georges Perec (2009), é um destes exemplos. O cenário desse livro é um prédio cuja estrutura se assemelha a um quadrado mágico de ordem 10, onde cada quadradinho representa um apartamento. A história de cada capítulo do livro, isto é, a que se passa em cada "apartamento", leva em consideração 42 restrições impostas que provêm de um total de 420 , originalmente separadas em 42 tabelas com 10 possibilidades cada $^{10}$. Cada capítulo, portanto, utiliza uma das 10 possibilidades de cada um dos 42 tipos, o que daria um total de $10^{42}$ possibilidades de inserção de elementos, tornando impossível, ao leitor, qualquer previsão do que se passará em cada apartamento. Além desta "narrativa combinatória", a trama não segue de um apartamento para o outro pela simples sequência numérica que usualmente ordena os capítulos de um livro: Perec elabora sua história segundo o circuito Hamiltoniano conhecido como poligrafia do cavalo ${ }^{11}$.

Dirigindo a este livro um olhar matemático contemporâneo e computacional, é possível perceber que este prédio - e, por conseguinte, sua estrutura narrativa - lembra uma matriz 10 x 10, na qual, a cada célula (apartamento/capítulo), são levadas informações programáveis (as restrições impostas). “O milagre é que essa poética que se poderia dizer

\footnotetext{
${ }^{10}$ Cada tabela é uma listagem referente a uma temática (como, por exemplo, posições diferentes do personagem e atividades que desenvolve), de modo que a conjunção desses elementos gera a micro-história daquele apartamento. O livro de Fux (2016) trata destas questões em maiores detalhes.

11 Trata-se de um princípio derivado de um clássico problema conhecido pelos jogadores de xadrez: fazer com que um cavalo percorra as 64 casas de um tabuleiro sem jamais parar mais de uma vez na mesma casa. No caso do livro, a ação segue o caminho que o cavalo faria, passando pelos 100 apartamentos, o que dá a ordem narrativa dos capítulos da história.
} 
artificiosa e mecânica dê como resultado uma liberdade e uma riqueza inventiva inesgotáveis" (CALVINO, 1991, p. 136) nas mãos de um escritor que se dedicou por anos aos quebracabeças e aos jogos de palavras.

Outra obra, Avalovara, do escritor brasileiro Osman Lins (2005), é uma história de amor com inspiração geométrica. A narrativa segue o desenho de uma espiral sobreposta a um quadrado.

\begin{abstract}
O poema fornece o esqueleto de uma geometria rigorosa e oculta, que o Autor revela numa espécie de guia metalinguístico do leitor, e que dá à narrativa um movimento espiralado, sem começo nem fim quando tomado em si mesmo. O limite está no fato de a espiral ser contida num quadrado, que por sua vez se repete em quadrados menores, cada um representando uma letra. O traçado da espiral vai tocando sucessivamente as letras e, cada uma destas, corresponde a uma linha da narrativa, voltando periodicamente em segmentos cada vez maiores (CANDIDO, 2005, p. 7).
\end{abstract}

Ler Avalovara é, pois, passear sobre esta espiral, juntando partes que compõem, no todo, a história de um homem (Abel) que amou três mulheres (duas no passado e uma no presente). Candido (2005), ao comentar esta obra de Lins, ressalta que, além de servir a uma estrutura narrativa original, a escolha por tais figuras geométricas traz também outras significações à história: a espiral lhe dá um ar de infinitude, de todo, de eterno; os quadrados, de completude, de parte de um todo, de limitação. Estas sensações, oriundas das formas geométricas, são metáforas das quais Lins se utiliza para falar dos três enamoramentos de Abel, uma vez que esse se dirige para seu amor presente trazendo consigo seus amores e vivências do passado: há fluxos temporais e períodos estáticos, sentimentos que permanecem e outros já superados, aquilo em que Abel está se tornando e o que ele já foi; todas estas dicotomias de sentimentos do protagonista dialogam com as formas da espiral e do quadrado.

Por fim, trazemos como exemplo O Castelo dos Destinos Cruzados, de Ítalo Calvino (2008). As personagens são as 72 cartas do tarô ${ }^{12}$, das quais 12 são narradoras e as demais são personagens das histórias. Organizando 60 dessas numa matriz M, quadrada de ordem 8, colocando apenas uma carta em cada célula $\mathrm{m}_{\mathrm{ij}}$ e deixando 4 delas desocupadas $\left(\mathrm{m}_{13}, \mathrm{~m}_{16}, \mathrm{~m}_{83}\right.$ e m86), Calvino estabelece o agrupamento de personagens de cada capítulo do livro. Cada capítulo conta uma história com 16 cartas que estão em colunas ou linhas consecutivas (colunas 1 e 2; 4 e 5; 7 e 8 e linhas 2 e 3; 4 e 5; 6 e 7, como se observa no esquema abaixo).

12 Calvino (2008) relata que utilizou, como personagens, as cartas do baralho de tarô pintadas por Bonifácio Bembo para os duques de Milão, por volta da metade do século XV. 

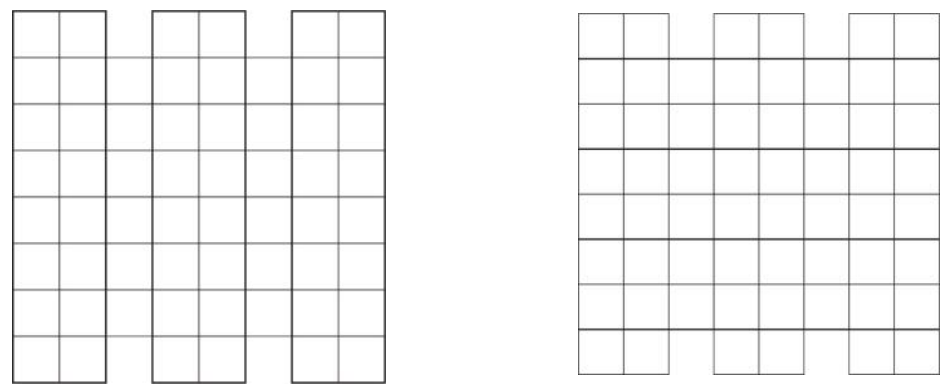

Figura 2 - Esquema de posição das cartas que compõem a narrativa de $O$ Castelo dos Destinos Cruzados Fonte: Juegos Matemáticos Ocultos en la Literatura (ODIFREDDI, 2007, p.80, adaptado).

Há, ainda, subconjuntos de quatro personagens que aparecem em mais de um capítulo, devido à sobreposição das linhas e colunas (por exemplo: as cartas colocadas nas células $\mathrm{m}_{21}$, $\mathrm{m}_{22}, \mathrm{~m}_{31}$ e $\mathrm{m}_{32}$ são personagens dos capítulos cujas histórias são formadas pelas cartas que estão nas linhas 2 e 3 e pelas que estão nas colunas 1 e 2). Devido a esta organização matemática e pela possibilidade - assumida pelo autor, mas não executada - de que as cartas poderiam ser distribuídas na matriz de outras maneiras, gerando outras narrativas, Odifreddi (2007) classificou este livro de Calvino como sendo uma "novela combinatória", cuja gênese o autor utilizaria novamente para compor outra obra sua: A Taberna dos Destinos Cruzados.

Calvino relatou o quanto lhe custou escrever estas histórias, pois não queria simplesmente pegar as cartas a esmo e criar algo a partir delas; buscava uma estrutura, uma rigidez narrativa que conseguiu atingir depois de várias tentativas de manipulação matemática das cartas:

\begin{abstract}
Assim, passava dias inteiros a compor e recompor o meu quebra-cabeça, imaginava novas regras do jogo, traçava centenas de esquemas, em quadrado, em losango, em estrela, mas sempre havia cartas essenciais que permaneciam fora e cartas supérfluas que ficavam no meio, e os esquemas se tornaram tão complicados (adquirindo às vezes até uma terceira dimensão, tornando-se cubos e poliedros) que eu próprio acabava me perdendo neles (CALVINO, 2008, p.155).
\end{abstract}

Esta declaração de Calvino sintetiza bem as obras que inventariamos nessa categoria: elas mostram o quanto seus autores buscaram, na Matemática, inspiração para romper as tradicionais estruturas narrativas.

Ainda que nem todos os leitores sejam capazes de perceber estas obras como tendo uma estrutura matemática, não podemos deixar de reconhecer nelas uma proximidade à construção de um sistema axiomático, uma vez que seus autores cuidadosamente estabeleceram regras para a escrita (axiomas), a partir das quais as histórias foram construídas (demonstradas) como uma dedução lógica delas, ou seja, sem as regras matemáticas que se autoimpuseram, as histórias não existiriam tais quais são.

\title{
4 Considerações finais
}


Este artigo apresentou alguns exemplos, dentre tantos possíveis, de obras literárias nas quais se evidenciam, de diferentes maneiras, conhecimentos matemáticos. A composição de um inventário com três distintas categorias não se propõe a ser uma catalogação definitiva, com limites bem definidos, pois tal rigidez não comunga com nenhuma manifestação artística - o que a literatura é, antes de mais nada; todavia, é um olhar construído pelo percurso de um caminho trilhado na pesquisa sobre esta temática.

Nosso intento foi comentar as semelhanças e diferenças entre os modos como a Matemática pode ser encontrada na Literatura, utilizando como critério de comparação o fato de ela ser intuitiva (um viés percebido pelos que estudam Matemática), citada textualmente (quando termos matemáticos compõem a narrativa e trazem, consigo, algo do conteúdo a que se referem) ou pensada como elemento narrativo (sendo, por isso, a estrutura da obra). Sendo assim, esperamos ter acenado para os leitores a existência de alguns entrelugares formados pela coadunação da Matemática e da Literatura; a primeira vem à cena com suas características racional, lógica e estruturante, enquanto que a segunda traz o simbólico, o intuitivo, o ilusório. A junção destes espaços enriquece tanto uma quanto a outra e pode, a partir do reconhecimento desta união, ter desdobramentos positivos para quem estuda, pesquisa ou ensina Matemática.

Como disse Eco (1986) na epígrafe que abriu este artigo, retirada de seu monumental romance $O$ Nome da Rosa, os livros abrem-se a significados, e tais significados (dos termos, do texto, das intenções do autor etc.) podem vir imbuídos de múltiplos segredos que a Matemática pode ajudar a decifrar.

\section{Referências}

ABBOTT, E. A. Planolândia: um Romance de Muitas Dimensões. São Paulo: Conrad, 2002.

ADAM, J.; HEIDMANN, U. O Texto Literário: por uma Abordagem Interdisciplinar. São Paulo: Cortez, 2011.

ADAMS, C. Zombies and Calculus. Woodstock: Princeton University Press, 2014.

ALMEIDA, M. da C. de. Um Alpendre Lilás para a Educação. In: FARIAS, C. A. Alfabetos da Alma: Histórias da Tradição na Escola. Porto Alegre: Sulina, 2006.

ARNOLD, D. S. Matemáticas Presentes em Livros de Leitura: Possibilidades para a Educação Infantil. 2016. 182 f. Dissertação (Mestrado Profissional em Ensino de Matemática) - Instituto de Matemática, Universidade Federal do Rio Grande do Sul, Porto Alegre, 2016.

BALladARES, B. L. Malba Tahan, Matemática e Histórias em Quadrinhos: Produção Discente de HQs em uma Colônia de Pescadores. 2014. 185f. Dissertação (Mestrado em Educação Matemática) - Instituto de Matemática, Universidade Federal do Rio Grande do Sul, Porto Alegre, 2014. 
BAUM, L. F. O Mágico de Oz. Rio de Janeiro: Zahar, 2013.

BORGES, J. L. O Livro dos Seres Imaginários. São Paulo: Companhia das Letras, 2007.

BOULLE, P. O Planeta dos Macacos. São Paulo: Aleph, 2015.

CALVINO, I. O Castelo dos Destinos Cruzados. São Paulo: Companhia das Letras, 2008.

CALVINO, Í. Seis Propostas para o Próximo Milênio. São Paulo: Companhia das Letras, 1991.

CAMPOS, R. S. P. de; MONTOITO, R. O Texto Alternativo ao Livro Didático como Proposta Interdisciplinar do Ensino de Ciências e Matemática. In: PIROLA, N. A. (Org.). Ensino de Ciências e Matemática IV. São Paulo: Cultura Acadêmica, 2010. p. 157-174.

CANDIDO, A. A espiral e o quadrado. In: LINS, O. Avalovara. São Paulo: Companhia das Letras, 2005.

CARROLL, L. A Caça ao Turpente. Além Paraíba: Interior edições, 1984.

CARROLL, L. Uma História Embrulhada. Campinas: Papirus, 1992.

CORRÊA, R. de A. Linguagem Matemática, Meios de Comunicação e Educação Matemática. In: NACARATO, A. M; LOPES, C. E. (Org.). Escritas e Leituras em Educação Matemática. Belo Horizonte: Autêntica, 2009. p. 93-100.

COSTA, P. M. B. J. S. Era uma Vez... Alfabetização Matemática e Contos de Fadas: uma Perspectiva para o Letramento na Infância. 2015. 168 f. Dissertação (Programa de Pós-graduação em educação) - Centro de Ciências Humanas e Sociais Aplicadas, Pontifícia Universidade Católica de Campinas, Campinas, 2015.

COUTINHO, L. Convite às Geometrias Não-Euclidianas. Rio de Janeiro: Interciência, 2001.

DI MARZO, L. Leer y Escribir Ficción en la Escula: Recorridos para Escritores en Formación. Buenos Aires: Paidós, 2013.

DOXIADIS, A; PAPADIMITRIOU, C. H. Logicomix: uma Jornada Épica em Busca da Verdade. São Paulo: Martins Fontes, 2010.

DRUMMOND, P. Leminiscata: o Enigma do Rio. Rio de Janeiro: Objetiva, 2007.

ECO, U. História das Terras e Lugares Lendários. Rio de Janeiro: Record, 2013.

ECO, U. O Nome da Rosa. Rio de Janeiro: Record, 1986.

ENZENSBERGER, H. M. O Diabo dos Números. São Paulo: Companhia das Letras, 2009.

FIELD, A. An Adventure Statistics: the Reality Enigma. Londres: Sage, 2016.

FONSECA, M. da C. F. R. A Educação Matemática e a Ampliação das Demandas de Leitura e Escrita da População Brasileira. In: FONSECA, M. da C. F. R. Letramento no Brasil: Habilidades Matemáticas. São Paulo: Global, 2004. p. 11-28. 
FONSECA, M. da C. F. R; CARDOSO, C. de A. Educação Matemática e Letramento: Textos para Ensinar Matemática e Matemática para Ler o Texto. In: NACARATO, A. M; LOPES, C. E. (Org.). Escritas e Leituras em Educação Matemática. Belo Horizonte: Autêntica, 2009. p. 63-76.

FUX, J. Matemática e Literatura: Jorge Luis Borges, George Perec e o OULIPO. São Paulo: Perspectiva, 2016.

GATTEGNO, J. L’univers de Lewis Carroll. Paris: José Corti, 1990.

GIORDANO, P. A Solidão dos Números Primos. Rio de Janeiro: Rocco, 2009.

GREEN, J. O Teorema Katherine. Rio de Janeiro: Intrínseca, 2013.

GUEDES, P. C; SOUZA, J. M. de. Leitura e Escrita são Tarefas da Escola e não só do Professor de Português. In: NEVES, I. C. B; SOUZA, J. V. et al (Org.). Ler e escrever: Compromisso de Todas as Áreas. Porto Alegre: Editora da UFRGS, 2011. p. 19-24.

GUEDJ, D. O Teorema do Papagaio. São Paulo: Companhia das Letras, 1999.

LEGUINA, J. Matemáticas y literatura. Unión - Revista Iberoamericana de Educación Matemática, n. 8, p. 53-62, 2006. Disponível em: <http://www.fisem.org/paginas/union/info .php?id=156>. Acesso em 13/04/2009.

LISPECTOR, C. Laços de Família. Rio de Janeiro: Rocco, 2009.

MACHADO, N. J. Matemática e Educação: Alegorias, Tecnologias, Jogo, Poesia. São Paulo: Cortez, 2012.

MACHADO, N. J. Matemática e Língua Materna: Análise de uma Impregnação Mútua. São Paulo, Cortez: 2001.

MARIA, L. de. O Clube do Livro: Ser Leitor - Que Diferença Faz? São Paulo: Globo, 2009.

MARTEL, Y. A Vida de Pi. Rio de Janeiro, Rocco: 2004.

MONTEMÓR. H.; FERNANDES, M. Literatura Infantil: uma Estratégia de Ensino nas Aulas de Matemática. Ideação, Foz do Iguaçu, v. 17, n. 2, p. 137- 157, 2015.

MARTÍNEZ, G. Borges y la Matemática. Buenos Aires: Eudeba, 2005.

MONTOITO, R. Chá com Lewis Carroll: a Matemática por trás da Literatura. Jundiaí: Paco, 2011.

MONTOITO, R. Euclid and His Modern Rivals (1879), de Lewis Carroll: Tradução e Crítica. 2013. 447 f. Tese (Programa de Pós-Graduação em Educação para a Ciência) - Faculdade de Ciências, Universidade Estadual Paulista, Bauru, 2013.

MORIN, E. Edgar Morin: Ética, Cultura e Educação. São Paulo: Cortez, 2011.

MURAKAMI, H. 1Q84, livro 2. Rio de Janeiro: Objetiva, 2013.

NACARATO, A. M; LOPES, C. E. (Org.). Escritas e Leituras em Educação Matemática. Belo Horizonte: Autêntica, 2009.

NEVES, I. C. B; SOUZA, J. V. et al. Ler e Escrever: Compromisso de Todas as Areas. Porto Alegre: Editora da UFRGS, 2011. 
ODIFREDDI, P. Juegos Matemáticos Ocultos en la Literatura. Barcelona: Octaedro, 2007.

OGAWA, Y. A Fórmula Preferida do Professor. São Paulo: Estação Liberdade, 2017.

PEREC, G. A Vida Modo de Usar. São Paulo: Companhia das Letras, 2009.

POE, E. A. Contos de Imaginação e Mistério. São Paulo: Tordesilhas, 2012.

SAINT-EXUPÉRY, A. de. O Pequeno Príncipe. Rio de Janeiro: Agir, 1988.

SANTOS, L. S. dos. A Geometria da Escola e a Utilização de Histórias em Quadrinhos nos Anos Finais do Ensino Fundamental. 2014. 120 f. Dissertação (Mestrado em Ensino de Ciências e Matemática) - Faculdade de Educação, Universidade Federal de Pelotas, Pelotas, 2014.

SANTOS, S. A. Explorações da Linguagem Escrita nas Aulas de Matemática. In: NACARATO, A. M; LOPES, C. E. (Org.). Escritas e Leituras em Educação Matemática. Belo Horizonte: Autêntica, 2009.

SAMPAIO, J. C. V. Uma Introdução à Topologia Geométrica: Passeios de Euler, Superficies e o Teorema das Quatro Cores. São Carlos: EDUFScar, 2008.

STADLER, M. M. Las Matemáticas de la Literatura. Disponível em: <http://www.ehu.es/ mtwm astm/Paseo0607.pdf>. Acesso em 13/04/2009.

TAHAN, M. O Homem que Calculava. Rio de Janeiro: Record, 2012.

URBANEJA, P. M. G. Matemática y Lenguaje y Matemática como Lenguaje. Disponível em <http://divulgamat.ehu.es/weborriak/TestuakOnLine/Hasierakolkasgaiak/LecInaugl0506PMGU.pdf> Acesso em 13/04/2009.

VERGANI, T. A Criatividade como Destino: Transdisciplinaridade, Cultura e Educação. São Paulo: Editora Livraria da Física, 2009.

VIANA, F. R. O Uso de Portfólios na Avaliação em Matemática como Motivador para Escrita dos Alunos sobre sua Aprendizagem e Reflexão da Prática Pedagógica. 2017. 120 f. Dissertação (Mestrado em Ensino de Ciências e Matemática) - Faculdade de Educação, Universidade Federal de Pelotas, Pelotas, 2017.

Submetido em 03 de Setembro de 2018. Aprovado em 17 de Fevereiro de 2019. 